\title{
Pityriasis Lichenoides and Cutaneous T Cell Lymphoma: An Update on the Diagnosis and Management of the Most Common Benign and Malignant Cutaneous Lymphoproliferative Diseases in Children
}

\author{
Markus D. Boos • Sara S. Samimi • Alain H. Rook • \\ Albert C. Yan • Ellen J. Kim \\ Published online: 21 August 2013 \\ (C) Springer Science+Business Media New York 2013
}

\begin{abstract}
Although more common with advanced age, the entire spectrum of benign and malignant cutaneous lymphoproliferative disorders can present in the pediatric population. Nevertheless, these conditions are often mistaken for other more common, benign dermatoses, resulting in delayed diagnosis. Standardized management of these conditions is also lacking. The purpose of this review is to provide an update on the most common benign and malignant cutaneous lymphoproliferative disorders in children: pityriasis lichenoides and mycosis fungoides. The presentation, evaluation and management of each of these conditions are discussed.
\end{abstract}

Keywords Cutaneous T cell lymphoma · Pityriasis lichenoides $\cdot$ Cutaneous lymphoproliferative disease

$\begin{array}{ll}\text { Abbreviations } \\ \text { BSA } & \text { Body surface area } \\ \text { CT } & \text { Computerized tomography } \\ \text { CTCL } & \text { Cutaneous T cell lymphoma } \\ \text { EBV } & \text { Epstein-Barr virus } \\ \text { FM } & \text { Follicular mucinosis }\end{array}$

M. D. Boos · S. S. Samimi · A. H. Rook • E. J. Kim Department of Dermatology, Perelman School of Medicine at the University of Pennsylvania, Philadelphia, PA, USA

M. D. Boos $\cdot$ S. S. Samimi • A. C. Yan

Section of Dermatology, Department of Pediatrics, The Children's Hospital of Philadelphia, Philadelphia, PA, USA

\section{D. Boos $(\bowtie)$}

Department of Dermatology, Hospital of the University of Pennsylvania, 3600 Spruce Street, 2 Maloney Building, Philadelphia, PA 19104, USA

e-mail: markus.boos@uphs.upenn.edu

$\begin{array}{ll}\text { FMF } & \text { Folliculotropic mycosis fungoides } \\ \text { FUMHD } & \text { Febrile ulceronecrotic Mucha-Haberman disease } \\ \text { HHV } & \text { Human herpesvirus } \\ \text { HIV } & \text { Human immunodeficiency virus } \\ \text { HLA } & \text { Human leukocyte antigen } \\ \text { HSV } & \text { Herpes simplex virus } \\ \text { IVIG } & \text { Intravenous immunoglobulin } \\ \text { MF } & \text { Mycosis fungoides } \\ \text { MMR } & \text { Measles mumps and rubella } \\ \text { nbUVB } & \text { narrow band ultraviolet B } \\ \text { NCCN } & \text { National comprehensive cancer network } \\ \text { NHL } & \text { Non-Hodgkins lymphoma } \\ \text { NM } & \text { Nitrogen mustard } \\ \text { PET } & \text { Positron emission tomography } \\ \text { PL } & \text { Pityriasis lichenoides } \\ \text { PLC } & \text { Pityriasis lichenoides chronica } \\ \text { PLEVA } & \text { Pityriasis lichenoides et varioliformis acuta } \\ \text { PUVA } & \text { Psoralen with ultraviolet A } \\ \text { TCR } & \text { T cell receptor } \\ \text { TNF } & \text { Tumor necrosis factor } \\ \text { VZV } & \text { Varicella zoster virus }\end{array}$

\section{Introduction}

Non-Hodgkins lymphoma (NHL) comprises $7 \%$ of all childhood malignancies. Amongst these, primary cutaneous lymphoproliferative disorders account for fewer than $10 \%$ of disease cases, making cutaneous lymphoma an extremely rare occurrence in children [1]. Although more common with advanced age, the entire spectrum of cutaneous lymphoproliferative disorders can nevertheless present in children and adolescents. These entities range from neoplasms such as mycosis fungoides, the most common cutaneous lymphoma in children, to rare diseases such as cutaneous B cell 
lymphoma, subcutaneous panniculitic T cell lymphoma, primary cutaneous aggressive epidermotropic CD8+ T cell lymphoma, anaplastic large cell lymphoma and NK-T lymphomas. These clearly malignant conditions exist along a spectrum of benign or clinically indolent lymphoproliferative entities including pityriasis lichenoides, follicular mucinosis, lymphomatoid papulosis and CD4+ small-medium pleomorphic $\mathrm{T}$ cell lymphoma [2]. Owing to their rarity and their propensity to mimic other more common, benign dermatoses of childhood, the diagnosis of cutaneous lymphoproliferative disease in children is both difficult and often delayed. Furthermore, treatment is typically not standardized due to a lack of comparative randomized control trials. The purpose of this review is to provide an update on the most common benign and malignant cutaneous lymphoproliferative disorders in children: pityriasis lichenoides and mycosis fungoides.

\section{Pityriasis Lichenoides}

Pityriasis Lichenoides (PL) was first described by Neisser and Jadassohn in 1894. This benign entity is typically classified into two main variants: pityriasis lichenoides et varioliformis acuta (PLEVA) and pityriasis lichenoides chronica (PLC). PLEVA and PLC are thought to lie on a disease spectrum, with PLEVA being more acute and symptomatic and PLC being more chronic in nature, but some patients may show features of both $[3 \cdot, 4]$. In a recent review by Hapa et al., of 24 patients (ages $2-14$, with a median age of 7 years) with pityriasis lichenoides, PLC was more common than PLEVA ( $62.5 \%$ to $25 \%$, respectively), with features of both in a small subset of patients $(2.5 \%)$ [5•]. In contrast, a larger retrospective review of 124 patients in 2007 identified PLEVA in $57.3 \%$ and PLC in $37 \%$ of patients, with features of both seen in the remainder. PLEVA exhibits a younger median age of onset (60 months) compared to PLC (72 months), with a median duration of disease ranging from 18 to 20 months [4]. Both subtypes present more commonly in the spring and fall $[4,5 \cdot]$.

Clinically, PLEVA is characterized by the acute onset of pruritic and at times painful, symptomatic papulovesicles with necrotic, ulcerative or hemorrhagic changes. In its early presentations, the condition may be confused with varicella. Patients with PLEVA, however, lack the typical fever and mucous membrane involvement seen in varicella, and the course of PLEVA is considerably more prolonged. In contrast, the hallmark of PLC is recurrent crops of asymptomatic, scaly, red-brown or hypopigmented papules and plaques that flatten or regress over a period of weeks. Clinically, the papulosquamous appearance of this condition may resemble pityriasis rosea or hypopigmented mycosis fungoides. Lesions of both PLEVA and PLC may be present at all stages of development.
Notably, the histopathology of these entities can overlap. Examination reveals focal parakeratosis, mild to moderate acanthosis, a variably intense lichenoid tissue reaction with dyskeratotic keratinocytes, and erythrocyte extravasation. As a rule, more subtle changes are noted in PLC with a superficial lichenoid lymphocytic infiltrate, while these histologic findings may be more exuberant in PLEVA, exhibiting a more intense lichenoid infiltrate, deep dermal perivascular lymphocytes, epidermal necrosis, hemorrhagic crusting and ulceration.

PLEVA and PLC are regarded as benign reactive lymphoproliferative disorders, and several theories regarding their etiology have been postulated. Specifically, PLEVA and PLC have been proposed to represent an inflammatory reaction triggered by an infectious agent or medication, or secondary to a T cell dyscrasia. A history of a preceding URI is reported in $33 \%$ of cases, and preceding drug or vaccination in $20 \%$ of cases [5•]. Suspected infectious triggers include varicella zoster virus (VZV) [6], Human herpesvirus (HHV)-8 [7], streptococcal pharyngitis, Toxoplasma gondii, parvovirus B19, Epstein-Barr virus (EBV), and human immunodeficiency virus (HIV) [8]. Implicated medications and vaccinations include subcutaneous immunoglobulin [9] and the measles, mumps and rubella (MMR) vaccine $[10,11]$. T cell clonality has been detected in patients with PL, supporting an alternate theory that these entities represent a lymphoproliferative rather than an inflammatory process. In tissue samples from 14 patients with PLEVA and 13 patients with PLC, $57 \%$ of patients with PLEVA had evidence of a monoclonal $\mathrm{T}$ cell receptor gene rearrangement in comparison to $8 \%$ with PLC [12]. In contrast, in another study of 23 patients with a history of PLEVA and PLC, only one patient with PLEVA had evidence of a positive $\mathrm{T}$ cell receptor (TCR) gene rearrangement [7]. Those patients so identified were thought to have a viral trigger. Currently, it is unclear if T cell clonality in $\mathrm{PL}$ is dependent upon a specific disease trigger. It is also unknown whether those patients identified as having a clonal population may be at increased risk of developing a secondary lymphoproliferative disease.

Though PL is more commonly identified in and associated with children, it also occasionally affects adolescents and adults. However, its presentation and response to treatment vary. In a study of 57 patients, ( 25 children and 32 adults) diagnosed with PL, children were more likely than adults to have more prominent dyspigmentation (notably hypopigmentation). More extensive cutaneous involvement, especially facial involvement, was also more likely to occur in children. Children generally had a poorer response to conventional treatments [13].

First-line treatment options for both PLEVA and PLC include oral antibiotics with or without topical corticosteroids or topical immune modulators. Erythromycin is the most common antibiotic administered, with patients demonstrating 
greater than $50 \%$ improvement in their skin in $64 \%$ at 1 month, $73 \%$ at 2 months and $83 \%$ at 3 months [5•]. Cephalexin, amoxicillin-clavulanic acid, cefaclor, tetracycline, and azithromycin have also been used with some success [14]. Second-line treatment options include ultraviolet B (UVB) and psoralen with ultraviolet A (PUVA) phototherapy, though their success and tolerability may vary based on the age of the patient [15]. Narrowband (nb)UVB alone has been successful in $44-48 \%$ of patients with PLC [16•]. Third-line agents include methotrexate, acitretin, dapsone, or cyclosporine. Up to $77 \%$ of patients have evidence of disease recurrence after complete clearance with appropriate treatment [4].

Febrile ulceronecrotic Mucha-Haberman disease (FUMHD) is a severe variant of PLEVA that deserves special mention. It may follow a diagnosis of PLEVA $[17,18]$ or occur de novo [19]. Affected patients exhibit rapid onset of necrotic papules coalescing into large ulcerations with numerous systemic symptoms including markedly high fevers [8]. It tends to occur more commonly in children and young adults, with the youngest case reported most recently of a 34-month-old [17]. Rarely, FUMHD may clinically mimic Stevens-Johnson syndrome (SJS), given the extent of cutaneous involvement with epidermal necrosis [19]. Similar to PL, no clear triggers have been identified for FUHMD, though isolated cases have demonstrated seropositivity to VZV [20] and Herpes Simplex Virus (HSV)-2 [21]. Treatment modalities for FUMHD may overlap with PL; however, given its severity with rapid progression, systemic complications, and potential fatality, more aggressive medications are utilized. Treatment options include Tumor Necrosis Factor (TNF)-alpha inhibitors [22], methotrexate $[17,19,23]$, prednisone [19], intravenous immune globulin (IVIG) and extracorporeal photopheresis [24].

\section{Cutaneous T Cell Lymphoma and Mycosis Fungoides}

Cutaneous T cell Lymphoma (CTCL) is a non-specific term that encompasses all extranodal $\mathrm{T}$ cell neoplasms that primarily involve the skin [25]. As such, CTCL includes both indolent and aggressive malignancies of varying clinical, histologic and immunophenotypic character. The overall incidence of CTCL in the United States is approximately 6.4 per million persons [26]. Although CTCL can occur in both adults and children, its incidence increases significantly with age, from an incidence of 0.4 per million persons in children less than 20 years old to an incidence of 24.6 per million persons in adults aged 70-79 years [26]. Notably, the incidence of CTCL appears to be increasing with time, though whether this is secondary to improvements in diagnosis or a specific etiologic factor is disputed [26].

Mycosis fungoides (MF) is the most common subset of CTCL in both adults and children. As with CTCL in general, MF is primarily a disease of advanced age. However, a notable portion of MF diagnoses are made in children, ranging from 2 to $16 \%$, depending on the population studied [27-31].

Mycosis fungoides has a protean presentation ranging from limited patch stage (T1a skin classification) disease to widespread erythroderma (T4 skin classification), with or without extracutaneous involvement. Classically, early stage MF is characterized by scattered patches and plaques that favor sun-protected or so-called "double-covered" areas such as the buttocks and upper thighs (Fig. 1). Patches typically appear as well-demarcated, erythematous areas with overlying scale and variable pruritus. Atrophy or poikiloderma may be appreciated in these localized areas. Plaque-stage disease may have a similar distribution, but is characterized by thickened red-brown skin that may assume a more annular appearance. More advanced stage disease presents as tumors or nodules that frequently ulcerate, or as frank erythroderma, often with accompanying systemic involvement. The clinical staging system for MF is summarized in Table 1.

The clinical manifestations of MF in children are diverse. While many patients display classic chronic eczematous or psoriasiform patch/plaque stage disease, they may also present with folliculotropic, poikilodermatous, isolated acral (pagetoid reticulosis, Woringer-Kolopp type) or leukemic (Sezary syndrome) variants [28, 32, 33]. Purpuric variants, including a case of MF mimicking a pigmented purpuric dermatitis, have also been reported $[34,35]$. The occurrence of MF in family members (parent-child or siblings) has also been described; a disease susceptibility secondary to specific human leukocyte antigen (HLA) alleles has been proposed to explain this phenomenon [36-39]. In these instances, the age of onset is often in earlier adulthood than in sporadic cases, typically presenting in the fourth and fifth decade of life, though differences in clinical behavior have not been identified [37, 38]. However,

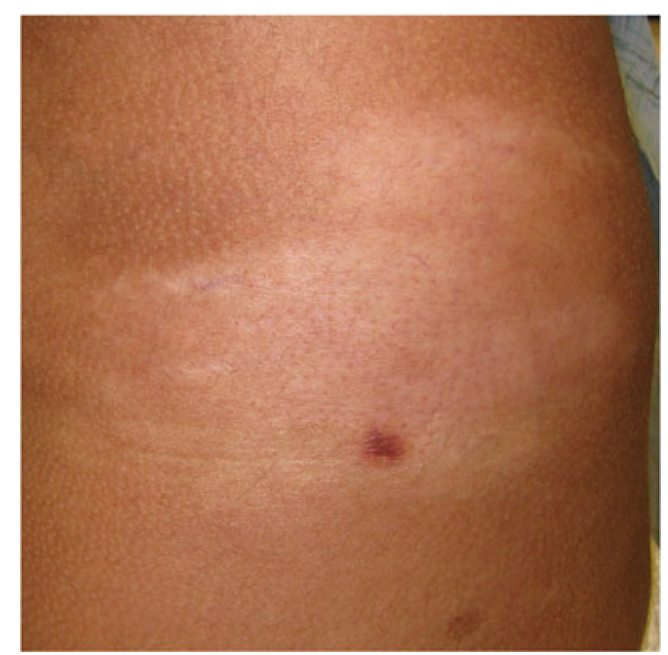

Fig. 1 Hypopigmented MF in a child. An ill-defined hypopigmented patch without scale or atrophy is present on the left upper thigh. The hyperpigmented macule at the inferior aspect of the lesion represents a previous biopsy site 
Table 1 TNMB classification and clinical staging of mycosis fungoides (adapted from NCCN clinical practice guidelines in oncology: NonHodgkin's lymphomas, version 1.2013)

\begin{tabular}{|c|c|c|c|c|}
\hline \multicolumn{5}{|c|}{ TNMB Classification } \\
\hline Skin & \multicolumn{4}{|c|}{ Description } \\
\hline $\mathrm{T} 1$ & \multicolumn{4}{|c|}{$\begin{array}{l}\text { Patches }(\mathrm{T} 1 \mathrm{a}) \text {, papules and/or plaques }(\mathrm{T} 1 \mathrm{~b}) \text { covering } \\
<10 \% \text { total body surface area }\end{array}$} \\
\hline $\mathrm{T} 2$ & \multicolumn{4}{|c|}{$\begin{array}{l}\text { Patches (T2a), papules and/or plaques (T2b) covering } \\
\geq 10 \% \text { total body surface area }\end{array}$} \\
\hline $\mathrm{T} 3$ & \multicolumn{4}{|c|}{ One or more tumors ( $\geq 1 \mathrm{~cm}$ in diameter) } \\
\hline $\mathrm{T} 4$ & \multicolumn{4}{|c|}{$\begin{array}{l}\text { Erythroderma (erythema involving } \geq 80 \% \text { total } \\
\text { body surface area) }\end{array}$} \\
\hline \multicolumn{5}{|l|}{ Nodes } \\
\hline No & \multicolumn{4}{|c|}{ No clinically abnormal lymph nodes identified } \\
\hline N1 & \multicolumn{4}{|c|}{$\begin{array}{l}\text { Atypical lymph nodes, histopathology Dutch Grade } 1 \\
\text { or NCI LN 0-2 }\end{array}$} \\
\hline $\mathrm{N} 2$ & \multicolumn{4}{|c|}{$\begin{array}{l}\text { Atypical lymph nodes, histopathology Dutch Grade } 2 \\
\text { or NCI LN } 3\end{array}$} \\
\hline $\mathrm{N} 3$ & \multicolumn{4}{|c|}{$\begin{array}{l}\text { Atypical lymph nodes, histopathology Dutch Grade } \\
\text { 3-4 or NCI LN } 4\end{array}$} \\
\hline $\mathrm{NX}$ & \multicolumn{4}{|c|}{ Abnormal lymph nodes without histopathologic evaluation } \\
\hline \multicolumn{5}{|c|}{ Visceral } \\
\hline M0 & \multicolumn{4}{|c|}{ No visceral organ involvement } \\
\hline M1 & \multicolumn{4}{|c|}{ Visceral involvement with histologic confirmation } \\
\hline MX & \multicolumn{4}{|c|}{ Visceral involvement without histologic confirmation } \\
\hline \multicolumn{5}{|l|}{ Blood } \\
\hline B0 & \multicolumn{4}{|c|}{$\begin{array}{l}\text { Absence of significant blood involvement } \leq 5 \% \text { of } \\
\text { peripheral blood lymphocytes are Sezary cells }\end{array}$} \\
\hline B1 & \multicolumn{4}{|c|}{$\begin{array}{l}\text { Low blood tumor involvement; }>5 \% \text { of peripheral } \\
\text { blood lymphocytes are Sezary cells, but does not } \\
\text { meet classification as B2 }\end{array}$} \\
\hline $\mathrm{B} 2$ & \multicolumn{4}{|c|}{$\begin{array}{l}\text { High blood tumor involvement; } \geq 1000 / \mathrm{mcL} \text { Sezary } \\
\text { cells or } \geq 40 \% \text { CD } 4+/ \mathrm{CD} 7 \text { - or } \geq 30 \% \text { CD } 4 \\
+ \text { CD26- cells identified in peripheral blood }\end{array}$} \\
\hline \multicolumn{5}{|c|}{ Clinical Staging of Mycosis Fungoides } \\
\hline & $\mathrm{T}$ & $\mathrm{N}$ & M & $\mathrm{B}$ \\
\hline IA & 1 & 0 & 0 & $0-1$ \\
\hline IB & 2 & 0 & 0 & $0-1$ \\
\hline IIA & $1-2$ & $1-2$ & 0 & $0-1$ \\
\hline IIB & 3 & $0-2$ & 0 & $0-1$ \\
\hline IIIA & 4 & $0-2$ & 0 & 0 \\
\hline IIIB & 4 & $0-2$ & 0 & 1 \\
\hline $\mathrm{IVA}_{1}$ & $1-4$ & $0-2$ & 0 & 2 \\
\hline $\mathrm{IVA}_{2}$ & $1-4$ & 3 & 0 & $0-2$ \\
\hline IVB & $1-4$ & $0-3$ & 1 & $0-2$ \\
\hline
\end{tabular}

$\mathrm{NCI}=$ National Cancer Institute, $\mathrm{LN}=$ lymph node

it is notable that "familial MF" has also been reported in siblings during childhood, or affecting both adult parents and their young children, though this occurrence is quite rare $[36,37,39]$.
Unilesional and hypopigmented MF are two notable variants in children and adolescents that occur with greater frequency than in adults [34, 40, 41 • 42-44]. The prevalence of the hypopigmented form in children with MF was initially estimated at approximately $20 \%$, but it likely represents the most common type of MF in children [29, 30, 41•, 42]. This variant presents as hypopigmented macules and patches accentuated in sun-protected areas, typically without secondary changes of scale or atrophy [40]. Hypopigmented lesions occur alone or concomitantly with classic erythematous or hyperpigmented patches and plaques of MF. Pruritus is often absent. Hypopigmented MF is more common in dark-skinned patients, but is known to occur in Caucasians, as well [27, 30, 40, 43, 45]. Notably, a series of three children with MF characterized by scaly red-brown macules and papules suggestive of PL has also been described [46]. Despite the fact that PL typically has an indolent course, it is important to consider MF in the differential diagnosis of PL-like lesions in children to ensure proper diagnosis. Regardless of clinical appearance, multiple studies have shown that the majority of children diagnosed with MF have early stage disease (IA, IB or IIA) [28-30, 33, 41 • 42]. Indeed, a more recent study analyzed the clinical and histologic characteristics of 22 children with MF registered with the International Childhood Registry for Cutaneous Lymphomas, and showed that patch stage and hypopigmented lesions were the most common presentations in this age group [41•].

Folliculotropic MF (FMF) is an uncommon variant characterized by follicular plugging with evidence of comedones, milia and cysts, which can be readily confused with acne. In certain instances, it may evolve to discrete alopecic, indurated red plaques. FMF is associated with decreased survival [47]. Criteria for the diagnosis ofFMF overlap considerably with follicular mucinosis (FM), a reactive process that also involves hair follicles. Whether follicular mucinosis represents a benign idiopathic condition or an early form of mycosis fungoides, however, remains controversial [48-50]. An essential component of this controversy is the presence of two distinct variants of FM that exhibit different clinical behavior: FM in young patients with limited head and neck involvement and an excellent prognosis (idiopathic FM) vs. FM in older patients (greater than 40 years old) with disseminated lesions and an increased risk of progression to MF [50, 51]. Importantly, these two subtypes cannot be distinguished based on $\mathrm{T}$ cell clonality $[50,51]$. Recently two studies analyzed the clinicopathologic features of FM in children to better understand the natural course of FM and whether it is related to MF in this age group [52, 53*•]. In each of these retrospective studies, a cohort of children with a diagnosis of follicular mucinosis was identified. A minority of these patient had associated mycosis fungoides (based on either classic histopathologic findings or meeting diagnostic criteria outlined by the International Society of Cutaneous Lymphomas), and all 
were treated with conservative topical therapy (see below). In the majority of cases, the lesions resolved without recurrence and were infrequently associated with other hematologic malignancies $[52,53 \bullet \cdot]$. Both studies concluded that FM could not be equated to early folliculotropic MF in children, and that in most cases it should be regarded as a benign entity. As such, aggressive therapy should be avoided. However, patients should be followed closely for potential malignant transformation or associated disease $[52,53 \bullet \bullet]$.

As a result of its clinical heterogeneity, as well as its relative rarity, MF is often mistaken for more common, benign dermatoses in children. The differential diagnosis of MF in children may include atopic dermatitis, psoriasis, tinea corporis and pityriasis rubra pilaris [28, 30, 35]. Vitiligo, pityriasis alba, PLC, post-inflammatory hypopigmentation, progressive macular hypomelanosis, leprosy, morphea and sarcoidosis are considerations when the hypopigmented form predominates [40, 43, 45].

A diagnosis of MF can be facilitated via histologic examination of an adequate skin specimen. MF is characterized by a lichenoid infiltrate of lymphocytes with prominent epidermotropism. These epidermal lymphocytes are often atypical in appearance, being of variable size and with hyperchromatic or cerebriform nuclei [25]. Occasionally, these lymphocytes aggregate in clusters to form Pautrier's microabscesses within the epidermis. A notable histologic feature of MF is the relative absence of spongiosis in relation to the epidermal infiltrate. Additional features suggestive of MF include socalled "tagging" of the dermal-epidermal junction by atypical lymphocytes, as well as fibrosis of the papillary dermis [25, 46]. Immunohistochemical studies may augment routine histology, demonstrating an increased CD4 to CD8 ratio in the epidermis and dermis. In contrast to classic MF, hypopigmented MF is more frequently characterized by a predominantly CD8+ cellular phenotype, though this does not appear to change disease course or prognosis [40, 43, 45]. Although identification of T cell receptor (TCR) clonality by PCR may be supportive of the diagnosis of MF, it should be noted that cases of MF may lack this finding and it is not diagnostic of the condition [28, 29, 42]. Furthermore, TCR clonality has been documented in various benign, reactive conditions $[54,55]$. Nevertheless, clonality may serve as a useful marker to monitor for residual disease after therapy, if initially present [56]. In instances where histologic findings are not entirely diagnostic, but clinical suspicion persists or patients are refractory to therapy for an alternate diagnosis, repeat biopsy or biopsies over time is recommended, with patients off topical therapies for at least 3 weeks prior.

Evaluation of children with CTCL is not standardized. However, in our practice we adhere closely to suggested National Comprehensive Cancer Network (NCCN) clinical practice guidelines for the management of MF in adults [57]. Evaluation begins with a comprehensive medical history, with special attention to recent " $\mathrm{B}$ " symptoms, including fever, weight loss, night sweats, fatigue, and pruritus. A complete physical exam is performed, specifically noting morphology, distribution and body surface area involved, as well as the presence of hepatosplenomegaly and lymphadenopathy. Laboratory workup for all patients includes a complete blood count, comprehensive metabolic panel and lactate dehydrogenase. For patients with limited patch stage disease (T1a) with no " $\mathrm{B}$ " symptoms, no additional screening is performed. In patients with limited patch disease with "B" symptoms, limited plaque (T1b) or more extensive patch disease (T2a) or plaque disease (T2b), tumors (T3) or erythroderma (T4), flow cytometry and TCR gene rearrangement studies of both blood and lesional skin are performed to evaluate for clonality and peripheral blood involvement.

The decision to employ full-body imaging via computerized tomography (CT) or CT/PET (positron emission tomography) is based on the likelihood of systemic involvement after preliminary evaluation outlined above. In our practice, we perform PET/CT imaging in patients with patch or plaque disease with $>20 \%$ body surface area (BSA), or in patients with $\mathrm{T} 3$ or T4 disease. In contrast, we defer imaging children with $\mathrm{T} 1$ or $\mathrm{T} 2$ disease with $<20 \%$ BSA involvement. Additionally, owing to its typically indolent clinical course, we defer PET/CT in children with hypopigmented MF, even if BSA involvement is $>20 \%$. The decision to image children via $\mathrm{CT}$ scan is one that should be done with a clear understanding of the risks involved. A recent retrospective cohort study demonstrated a positive association between ionizing radiation from $\mathrm{CT}$ scans and the development of either leukemia or brain cancer in persons less than 22 years of age [58]. Specifically, the authors estimated that the amount of radiation in two to three head CTs results in a three-fold increase in the risk of brain tumors, while the radiation of five to ten head CTs triples the risk of leukemia [58]. The authors of this study acknowledged that the relative incidence of these conditions is low at baseline, but estimated that one extra case of both leukemia and brain malignancy would occur for every 10,000 head CT scans [58]. These findings are supported by a second retrospective study that similarly identified an increased risk of radiation-induced malignancy in children undergoing CT scans [59・•]. Notably, abdominal/pelvic imaging appeared to be positively associated with an increased risk of solid tumors, while an increased risk of brain cancer and leukemias was associated with head CT scans (the most commonly performed CT scan in children) [59••]. Both studies contended that CT imaging should be limited as much as possible in children. We concur with this assessment; these risks may be even more pronounced in our patient population, where total body CT imaging is performed. Therefore, 
weighing the risks and benefits of multiple CT scans is an important consideration in the continued management of patients with MF. Alternative modalities for staging and followup that limit ionizing radiation should be employed as much as possible. Nevertheless, staging is vital in patients with T3 or T4 disease, and the benefits of imaging likely outweigh the risk of secondary malignancy due to radiation.

Treatment of MF is challenging, and a recent meta-analysis was unable to identify a single therapeutic regimen that resulted in improved disease-free interval or overall survival [60]. Therefore, goals of MF treatment should emphasize control of symptoms and improved quality of life, while minimizing the risks associated with therapy. Management of MF in children depends on disease stage. For limited disease (stages IA-IIA), skin-directed therapy is an appropriate first line approach. Options include potent topical steroids, topical nitrogen mustard, phototherapy, or localized radiotherapy [28, 41, $61-64]$. When deciding between these modalities, side effect profiles are a central consideration. Excessive use of potent topical steroids such as clobetasol is associated with skin atrophy and dyspigmentation, but in children it may also induce adrenal suppression over time when applied to a significant body surface area $[65,66]$. Topical nitrogen mustard (NM) may therefore be a reasonable alternative. A study by Kim et.al. found that in all patients treated with NM as initial therapy, an $83 \%$ response rate was achieved, with $50 \%$ of patients demonstrating a complete response to therapy [62]. Moreover, side effects,such as development of secondary cutaneous malignancy, irritant and allergic contact dermatitis were infrequent; these were no more common in children than adults [62]. Importantly, bone marrow suppression and other evidence of systemic absorption were not noted in children using this chemotherapeutic agent, though periodically evaluating children with a complete blood count and metabolic panel while using topical NM is advised [62]. Topical bexarotene or carmustine are alternate therapeutic considerations, though they carry their own unique risks, including potential hyperlipidemia with bexarotene and marked skin irritation and myelosuppression with carmustine [34, 65].

Phototherapy is an effective skin-directed therapy for MF $[41 \cdot, 64,65,67]$. PUVA has been shown in some studies to induce long-term remission lasting up to 10 years, but may be a suboptimal choice in children owing to side effects such as nausea, vomiting, phototoxicity and ocular sequelae [64]. Topical PUVA may mitigate some of these adverse effects. Alternatively, phototherapy with nbUVB also appears to be an effective option for controlling cutaneous disease in early stage patients $[27,34,63]$. Despite the efficacy of these treatments, the long-term risks of extended ultraviolet light exposure - especially with PUVA — must be measured against its apparent benefits. PUVA therapy is known to induce chronic photodamage (xerosis, telangiectases, lentigines), as well as cutaneous malignancies including melanoma [64,
67-69]. These adverse effects appear to be dose-dependent $[68,69]$. In contrast, nbUVB appears to be far less carcinogenic, but as adequate longitudinal studies have not been performed, it is unclear if this therapy may impart an increased risk of cutaneous malignancy later in life, particularly after multiple treatments [70]. As such, prolonged use of nbUVB should be performed with caution, and close clinical followup for the development of secondary skin malignancies is mandatory.

Patients with stage IIB or refractory stage IA-IIA disease may benefit from the addition of systemic agents including interferon-alpha, interferon-gamma, and bexarotene. For severe disseminated and/or extracutaneous disease, treatment in conjunction with a pediatric oncologist is recommended.

Few studies have directly assessed whether outcomes of children with MF differ from adults. It has been proposed that a diagnosis of MF in youth portends a worse outcome owing to the extended length of time for potential disease progression or transformation. However, a retrospective study of 58 patients diagnosed with MF before 35 years of age showed better overall and disease-specific survival compared to their older counterparts [61]. This was due primarily to the fact that younger patients usually present with earlier stage (T1) disease. Notably, none of these young patients with T1 disease showed progression to higher stages. In this study, association with other malignancies such as large cell lymphoma or Hodgkin's disease was rare [61]. Indirect evidence supporting a benign disease course in children with MF comes from studies showing that overall survival of patients with $\mathrm{T} 1$ patch stage disease does not differ from disease-free controls [47, 71-73]. Similarly, the hypopigmented variant of MF is associated with improved survival and reduced risk of disease progression [28, 47]. Although these studies were performed across all age groups, they provide optimism for the outcomes of most children with MF presenting with limited early disease. In contrast, those children with more advanced disease appear to have poor prognoses, similar to adults [28, 61]. Regardless, close follow up is mandatory in all patients. In our practice, when a patient's clinical course appears indolent, they are typically seen in follow-up every 3 months. Restaging may be necessary with acute worsening of disease.

\section{Conclusion}

PL and MF represent the most common benign and malignant lymphoproliferative diseases in children, respectively. Nevertheless, each of these entities has varied presentations ranging from asymptomatic, indolent lesions to widespread, debilitating eruptions. It is important to consider the long-term implications of these conditions (particularly MF) in children. While accurately identifying a given illness is important, the diagnosis of malignant conditions such as MF (no matter how 
indolent) may have significant consequences with respect to obtaining health insurance, employment etc. as an adult. Furthermore, the unclear association between PL and other hematologic malignancies may be cause for much concern. Goals of therapy include palliation of skin symptoms and skin appearance, while minimizing long-term cumulative side effects of potentially chronic therapies (such as actinic damage and the development of secondary malignancies). As a result, thoughtful, individualized workup, clinicopathologic correlation, counseling and therapeutic management is essential, as one approach does not fit all patients. Future multi-center collaborations will be required to identify those methods that will ultimately improve patient quality of life.

\section{Compliance with ethics Guidelines}

Conflict of Interest Markus D. Boos declares no conflicts of interest. Sara S. Samimi declares no conflicts of interest.

Alain H. Rook is a paid consultant for Regeneron and Celgene.

Albert C. Yan declares no conflicts of interest.

Ellen J. Kim has received a research grant from Kyowa Hakko Kirin to lead a Stage 3 CTCL trial (monies to institution, the University of Pennsylvania).

Human and Animal Rights and Informed Consent This article does not contain any studies with human or animal subjects performed by any of the authors.

\section{References}

Papers of particular interest, published recently, have been highlighted as:

- Of major importance

- Of importance

1. Gross TG, Termuhlen AM. Pediatric non-Hodgkin lymphoma. Curr Hematol Malig Rep. 2008;3:167-73.

2. Baum CL, Link BK, Neppalli VT, Swick BL, Liu V. Reappraisal of the provisional entity primary cutaneous $\mathrm{CD} 4+$ small/medium pleomorphic T-cell lymphoma: a series of 10 adult and pediatric patients and review of the literature. J Am Acad Dermatol. 2011;65:739-48.

3. - Fernandes NF, Rozdeba PJ, Schwartz RA, Kihiczak G, Lambert WC. Pityriasis lichenoides et varioliformis acuta: a disease spectrum. Int J Dermatol. 2010;49:257-61. This review delves into the clinical spectrum of PLEVA with Mucha Haberman disease as a severe variant, its proposed etiologies, histology and potential treatment regimens.

4. Ersoy-Evans S, Greco MF, Mancini AJ, Subași N, Paller AS. Pityriasis lichenoides in childhood: a retrospective review of 124 patients. J Am Acad Dermatol. 2007;56:205-10.

5. - Hapa A, Ersoy-Evans S, Karaduman A. Childhood pityriasis lichenoides and oral erythromycin. Pediatr Dermatol. 2012;29:71924. This retrospective analysis of 24 children demonstrated the efficacy of oral erythromycin in patients with both PLEVA and $P L C$, with a maximum response noted after administration for 3 months.
6. Cho E, Jun HJ, Cho SH, Lee JD. Varicella-Zoster virus as a possible cause of pityriasis lichenoides et varioliformis acuta. Pediatr Dermatol. 2012. doi:10.1111/j.1525-1470.2012.01821.x.

7. Kim JE et al. Pityriasis lichenoides et varioliformis acuta and pityriasis lichenoides chronica: comparison of lesional T-cell subsets and investigation of viral associations. J Cutan Pathol. 2011;38:649-56.

8. Bowers S, Warshaw EM. Pityriasis lichenoides and its subtypes. J Am Acad Dermatol. 2006;55:557-72. quiz 573-576.

9. Machan M, Loren R, Fraga G, Liu D. Pityriasis lichenoides et varioliformis acuta associated with subcutaneous immunoglobulin administration. J Am Acad Dermatol. 2012;67:e151-2.

10. Gunatheesan S, Ferguson J, Moosa Y. Pityriasis lichenoides et varioliformis acuta: a rare association with the measles, mumps and rubella vaccine. Australas J Dermatol. 2012;53:e76-8.

11. Gil-Bistes D, Kluger N, Bessis D, Guillot B, Raison-Peyron N. Pityriasis lichenoides chronic after measles-mumps-rubella vaccination. J Dermatol. 2012;39:492-3.

12. Weinberg JM et al. The clonal nature of pityriasis lichenoides. Arch Dermatol. 2002;138:1063-7.

13. Wahie S, Hiscutt E, Natarajan S, Taylor A. Pityriasis lichenoides: the differences between children and adults. Br J Dermatol. 2007;157:941-5.

14. Skinner RB, Levy AL. Rapid resolution of pityriasis lichenoides et varioliformis acuta with azithromycin. J Am Acad Dermatol. 2008;58:524-5.

15. Ersoy-Evans S, Altaykan A, Sahin S, Kölemen F. Phototherapy in childhood. Pediatr Dermatol. 2008;25:599-605.

16. • Ersoy-Evans S, Hapa AA, Boztepe G, Sahin S, Kölemen F. Narrowband ultraviolet-B phototherapy in pityriasis lichenoides chronica. J Dermatol Treat. 2009;20:109-13. This retrospective analysis of 25 patients demonstrated that nbUVB therapy is an effective mode of therapy with a complete response in $48 \%$ and a partial response of $44 \%$ of patients with PLC.

17. Perrin BS, Yan AC, Treat JR. Febrile ulceronecrotic MuchaHabermann disease in a 34-month-old boy: a case report and review of the literature. Pediatr Dermatol. 2012;29:53-8.

18. Tsianakas A, Hoeger PH. Transition of pityriasis lichenoides et varioliformis acuta to febrile ulceronecrotic Mucha-Habermann disease is associated with elevated serum tumour necrosis factor-alpha. Br J Dermatol. 2005;152:794-9.

19. Kaufman WS et al. Febrile ulceronecrotic Mucha-Habermann disease (pityriasis lichenoides et varioliformis acuta fulminans) presenting as Stevens-Johnson syndrome. Pediatr Dermatol. 2012;29:135-40.

20. Hervás JA et al. Varicella precipitating febrile ulceronecrotic MuchaHabermann disease. Pediatr Dermatol. 2012. doi:10.1111/pde.12008.

21. Smith JJL, Oliver GF. Febrile ulceronecrotic Mucha-Habermann disease associated with herpes simplex virus type 2. J Am Acad Dermatol. 2009;60:149-52.

22. Meziane L et al. Febrile ulceronecrotic Mucha-Habermann disease: treatment with infliximab and intravenous immunoglobulins and review of the literature. Dermatol Basel Switz. 2012;225:344-8.

23. Zhang L, Liang Y, Liu Y, Ma L. Febrile ulceronecrotic MuchaHabermann's disease with pulmonary involvement. Pediatr Dermatol. 2010;27:290-3.

24. Marenco F, Fava P, Fierro MT, Quaglino P, Bernengo MG. High-dose immunoglobulines and extracorporeal photochemotherapy in the treatment of febrile ulceronecrotic Mucha-Habermann disease. Dermatol Ther. 2010;23:419-22.

25. Willemze R. WHO-EORTC classification for cutaneous lymphomas. Blood. 2005;105:3768-85.

26. Criscione VD, Weinstock MA. Incidence of cutaneous T-cell lymphoma in the United States, 1973-2002. Arch Dermatol. 2007; 143:854-9.

27. Tan E, Tay YK, Giam YC. Profile and outcome of childhood mycosis fungoides in Singapore. Pediatr Dermatol. 2000;17:352-6. 
28. Wain EM, Orchard GE, Whittaker SJ, Spittle MF, Russell-Jones R. Outcome in 34 patients with juvenile-onset mycosis fungoides: a clinical, immunophenotypic, and molecular study. Cancer. 2003;98: 2282-90.

29. Quaglino P, Zaccagna A, Verrone A, Dardano F, Bernengo MG. Mycosis fungoides in patients under 20 years of age: report of 7 cases, review of the literature and study of the clinical course. Dermatol Basel Switz. 1999;199:8-14.

30. Nanda A et al. Mycosis fungoides in Arab children and adolescents: a report of 36 patients from Kuwait. Pediatr Dermatol. 2010;27:607-13.

31. Koch SE, Zackheim HS, Williams ML, Fletcher V, LeBoit PE. Mycosis fungoides beginning in childhood and adolescence. J Am Acad Dermatol. 1987;17:563-70.

32. Meister L, Duarte AM, Davis J, Perez JL, Schachner LA. Sézary syndrome in an 11-year-old girl. J Am Acad Dermatol. 1993; 28:93-5

33. Fink-Puches $\mathrm{R}$ et al. The spectrum of cutaneous lymphomas in patients less than 20 years of age. Pediatr Dermatol. 2004;21:525-33.

34. Yazganoglu KD, Topkarci Z, Buyukbabani N, Baykal C. Childhood mycosis fungoides: a report of 20 cases from Turkey. J Eur Acad Dermatol Venereol Jeadv. 2011. doi:10.1111/j.1468-3083.2011. 04383.x.

35. Hanna S, Walsh N, D'Intino Y, Langley RGB. Mycosis fungoides presenting as pigmented purpuric dermatitis. Pediatr Dermatol. 2006;23:350-4.

36. Baykal C, Büyükbabani N, Kaymaz R. Familial mycosis fungoides. Br J Dermatol. 2002;146:1108-10.

37. Hodak E et al. Familial mycosis fungoides: report of 6 kindreds and a study of the HLA system. J Am Acad Dermatol. 2005;52:393-402.

38. Schneider BF, Christian M, Hess CE, Williams ME. Familial occurrence of cutaneous $\mathrm{T}$ cell lymphoma: a case report of monozygotic twin sisters. Leukemia. 1995;9:1979-81.

39. Vassallo $\mathrm{C}$ et al. Mycosis fungoides in childhood: description and study of two siblings. Acta Derm Venereol. 2007;87:529-32.

40. Neuhaus IM, Ramos-Caro FA, Hassanein AM. Hypopigmented mycosis fungoides in childhood and adolescence. Pediatr Dermatol. 2000;17:403-6.

41. Pope E et al. Mycosis fungoides in the pediatric population: report from an international Childhood Registry of Cutaneous Lymphoma. J Cutan Med Surg. 2010;14:1-6. This retrospective analysis of 22 patients from the Childhood Registry of Cutaneous Lymphoma demonstrated that patch stage and hypopigmented MF were the most commonly represented variants in cases of pediatric $M F$.

42. Ben-Amitai D, David M, Feinmesser M, Hodak E. Juvenile mycosis fungoides diagnosed before 18 years of age. Acta Derm Venereol. 2003;83:451-6.

43. Ardigó M, Borroni G, Muscardin L, Kerl H, Cerroni L. Hypopigmented mycosis fungoides in Caucasian patients: a clinicopathologic study of 7 cases. J Am Acad Dermatol. 2003;49:264-70.

44. Ally MS et al. Solitary mycosis fungoides: a distinct clinicopathologic entity with a good prognosis. J Am Acad Dermatol. 2012;67: 736- 44.

45. Ranawaka RR, Abeygunasekara PH, de Silva MVC. Hypopigmented mycosis fungoides in type V skin: a report of 5 cases. Case Rep Dermatol Med. 2011;2011:1-6.

46. Ko JW, Seong JY, Suh KS, Kim ST. Pityriasis lichenoides-like mycosis fungoides in children. Br J Dermatol. 2000;142:347-52.

47. Agar NS et al. Survival outcomes and prognostic factors in mycosis fungoides/sezary syndrome: validation of the revised international society for cutaneous Lymphomas/European Organisation for Research and Treatment of Cancer Staging Proposal. J Clin Oncol. 2010;28:4730-9.

48. LeBoit PE. Alopecia mucinosa, inflammatory disease or mycosis fungoides: must we choose? And are there other choices? Am J Dermatopathol. 2004;26:167-70.
49. Vollmer RT. Mycosis fungoides and follicular mucinosis. Arch Dermatol. 2002;138:1613-4. author reply 1614-1615.

50. Brown HA, Gibson LE, Pujol RM, Lust JA, Pittelkow MR. Primary follicular mucinosis: long-term follow-up of patients younger than 40 years with and without clonal T-cell receptor gene rearrangement. J Am Acad Dermatol. 2002;47:856-62.

51. Cerroni L, Fink-Puches R, Bäck B, Kerl H. Follicular mucinosis: a critical reappraisal of clinicopathologic features and association with mycosis fungoides and Sézary syndrome. Arch Dermatol. 2002;138:182-9.

52. Zvulunov A, Shkalim V, Ben-Amitai D, Feinmesser M. Clinical and histopathologic spectrum of alopecia mucinosa/follicular mucinosis and its natural history in children. J Am Acad Dermatol. 2012;67: 1174-81.

53. • Alikhan A, Griffin J, Nguyen N, Davis DMR, Gibson LE. Pediatric follicular mucinosis: presentation, histopathology, molecular genetics, treatment, and outcomes over an 11-year period at the Mayo Clinic. Pediatr Dermatol. 2013;30:192-8. These two studies demonstrated that pediatric FM is infrequently associated with other hematologic malignancies and concluded that FM could not be equated with early folliculotropic MF in children.

54. Plaza JA, Morrison C, Magro CM. Assessment of TCR-beta clonality in a diverse group of cutaneous T-Cell infiltrates. J Cutan Pathol. 2008;35:358-65.

55. French LE et al. Identification of clonal T cells in the blood of patients with systemic sclerosis: positive correlation with response to photopheresis. Arch Dermatol. 2001;137:1309-13.

56. Garzon MC. Cutaneous T cell lymphoma in children. Semin Cutan Med Surg. 1999;18:226-32.

57. Zelenetz AD et al. Non-Hodgkin's lymphomas, version 3.2012. J Natl Compr Cancer Netw Jnccn. 2012;10:1487-98.

58. Pearce MS et al. Radiation exposure from CT scans in childhood and subsequent risk of leukaemia and brain tumours: a retrospective cohort study. Lancet. 2012;380:499-505.

59. • Miglioretti DL, et al. The use of computed tomography in pediatrics and the associated radiation exposure and estimated cancer risk. JAMA Pediatr. 2013:1-8. doi:10.1001/jamapediatrics.2013.311. These two studies demonstrated an increased risk of radiationinduced malignancy in the pediatric population following CT scans and argue for the responsible use of CT scans in the medical evaluation of children.

60. Weberschock T, et al. In: The Cochrane Collaboration \& Weberschock T, editors. Cochrane Database Syst. Rev. John Wiley \& Sons, Ltd, 2012. At <http://doi.wiley.com/10.1002/14651858. CD008946.pub2>.

61. Crowley JJ, Nikko A, Varghese A, Hoppe RT, Kim YH. Mycosis fungoides in young patients: clinical characteristics and outcome. J Am Acad Dermatol. 1998;38:696-701.

62. Kim YH, Martinez G, Varghese A, Hoppe RT. Topical nitrogen mustard in the management of mycosis fungoides: update of the Stanford experience. Arch Dermatol. 2003;139:165-73.

63. Kavala $\mathrm{M}$ et al. Treatment of childhood mycosis fungoides with narrow-band phototherapy. Int J Dermatol. 2009;48:203-4.

64. Pugashetti R, Koo J. Phototherapy in pediatric patients: choosing the appropriate treatment option. Semin Cutan Med Surg. 2010;29:115-20.

65. Berthelot C, Rivera A, Duvic M. Skin directed therapy for mycosis fungoides: a review. J Drugs Dermatol Jdd. 2008;7:655-66.

66. Zackheim HS, Kashani-Sabet M, Amin S. Topical corticosteroids for mycosis fungoides. Experience in 79 patients. Arch Dermatol. 1998;134:949-54.

67. Querfeld C et al. Long-term follow-up of patients with earlystage cutaneous T-cell lymphoma who achieved complete remission with psoralen plus UV-A monotherapy. Arch Dermatol. 2005;141:305-11. 
68. Stern RS, Nichols KT, Väkevä LH. Malignant melanoma in patients treated for psoriasis with methoxsalen (psoralen) and ultraviolet A radiation (PUVA). The PUVA follow-up study. N Engl J Med. 1997;336:1041-5.

69. Stern RS. Risk of squamous cell carcinoma and methoxsalen (Psoralen) and UV-A radiation (PUVA): a meta-analysis. Arch Dermatol. 1998;134:1582-5.

70. Hearn RMR, Kerr AC, Rahim KF, Ferguson J, Dawe RS. Incidence of skin cancers in 3867 patients treated with narrow-band ultraviolet B phototherapy. Br J Dermatol. 2008;159:931-5.
71. Kim YH, Jensen RA, Watanabe GL, Varghese A, Hoppe RT. Clinical stage IA (limited patch and plaque) mycosis fungoides. A long-term outcome analysis. Arch Dermatol. 1996;132:1309-13.

72. Kim YH, Liu HL, Mraz-Gernhard S, Varghese A, Hoppe RT. Longterm outcome of 525 patients with mycosis fungoides and Sezary syndrome: clinical prognostic factors and risk for disease progression. Arch Dermatol. 2003;139:857-66.

73. Talpur $\mathrm{R}$ et al. Long-term outcomes of 1,263 patients with mycosis fungoides and sezary syndrome from 1982 to 2009. Clin Cancer Res. 2012;18:5051-60. 